\title{
A study of the association between identity, life engagement and well-being among young Asian adults
}

\section{Elizaveta Berezina, Colin Mathew Hugues Desaguliers Gill \& Inna Bovina}

To cite this article: Elizaveta Berezina, Colin Mathew Hugues Desaguliers Gill \& Inna Bovina (2020): A study of the association between identity, life engagement and well-being among young Asian adults, Social Identities, DOI: 10.1080/13504630.2020.1783225

To link to this article: https://doi.org/10.1080/13504630.2020.1783225

曲 Published online: 26 Jun 2020.

Submit your article to this journal $\pi$

山 Article views: 9

Q View related articles ¿

View Crossmark data $־$ 


\title{
A study of the association between identity, life engagement and well-being among young Asian adults
}

\author{
Elizaveta Berezina ${ }^{a}{ }^{a}$, Colin Mathew Hugues Desaguliers Gill $\mathbb{1}^{b}$ and Inna Bovina (1D ${ }^{c}$

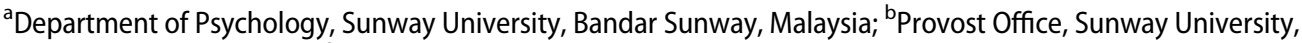 \\ Bandar Sunway, Malaysia; 'Department of Clinical and Legal Psychology, Moscow State University of \\ Psychology and Education, Moscow, Russia
}

\begin{abstract}
The eudaemonic tradition asserts that life engagement, that is the pursuit of a meaningful way of living, is an important element of well-being. Self-identity theory posits that individuals' identities significantly contribute to their sense of meaning and belonging, which in turn boost well-being. The present study aimed to establish the extent to which self-identities are predictors of wellbeing and whether they are subsumed within the life engagement construct. An opportunity sample of Singaporeans $(n=269)$ aged $18-35(M=23.88, S D=4.52)$ completed the Aspects of Identity Questionnaire, Warwick-Edinburgh Mental Well-Being Scale and Life Engagement Test. Correlational analysis showed that personal, social, relational and collective identities were significantly associated with life engagement and well-being. However, multiple regressions demonstrated that life-engagement subsumed collective and relational identity almost completely, and also accounted for a significant amount of the variance in personal and social identities in the prediction of well-being, broadly supporting the eudaemonic model. It was shown that social and personal identities were predictors of well-being beyond life engagement, possibly because these identities satisfy some of psychological needs that promote various benefits that are independent of life engagement, yet still important for wellbeing. It is suggested that these differences in the salience of identity types to well-being may be indicative of changes in the sense of identity among young Singaporeans that have arisen as a result of social policy or possibly changes in the ways of identity expression in the Internet. The implications of the findings are discussed and recommendations made for future research.
\end{abstract}

\section{ARTICLE HISTORY}

Received 16 October 2019

Accepted 10 June 2020

\section{KEYWORDS}

Self-identity theory; life engagement; well-being; eudaemonic model; millennials; societal change

\section{Introduction}

It is now widely accepted that psychological well-being is an essential part of a healthy life (World Health Organisation, 2014). Subjective well-being is commonly determined through the presence of positive affect, the absence of negative affect and a high level of life satisfaction (Diener \& Biswas-Diener, 2008; Sheldon \& Niemiec, 2006), however, there are still some debates on how to define and measure well-being and associated 
factors (Diener et al., 2018). The so-called hedonistic tradition focuses on the personal subjective perception of happiness and posits that well-being can be promoted through maximising one's feelings of happiness. However, Deci and Ryan (2008) suggest that subjective reports about happiness are not necessarily reliable evidence of psychological well-being, and propose another perspective that well-being is a process, not an outcome, which allows individuals to fulfil their potential through an active life and the actualisation of human potential. This approach to well-being falls within the eudaimonic tradition which is focused on actively achieving a meaningful and deeply satisfying way of living (Deci \& Ryan, 2008; Schueller \& Seligman, 2010).

Life events have a different influence on both affective and cognitive well-being (Luhmann et al., 2012). According to Kahneman and Deatlon (2010), income and education are closely related to the thoughts that people have about their life course, whereas health factors, care giving and loneliness are stronger predictors of the emotional quality of an individual's everyday experience. Although the satisfaction of such basic psychological needs is a strong predictor of well-being (Diener et al., 2010; Sheldon \& Niemiec, 2006; Smith, 2007), the three main factors that have the greatest impact on subjective and objective well-being are pleasure, meaningful activities and engagement, with the latter two having the strongest influence (Schueller \& Seligman, 2010).

Any activity that fulfils an individuals' potential through the ability to identify valuable goals and the capacity to achieve them, can broadly be considered as giving meaning to life. Engagement, on the other hand, implies active social involvement with people in different groups, so it follows that psychological well-being is in part dependent upon individuals' sense of social identity (e.g. Bratt, 2015; Friedman \& Kern, 2014: Greenaway et al., 2015; Outten \& Schmitt, 2015) which in turn is an aspect of a broader identity construct that combines personal, relational, collective and social identities (Cheek \& Briggs, 2013).

Personal Identity (the individuated self) is the lowest level of categorisation of the self and it can be defined as those characteristics that distinguish an individual from others (Burke \& Stets, 2009; Knowles \& Gardner, 2008) in terms of aspects like personal traits, values, abilities, personal aspirations and standards (Cheek et al., 2002). Ashmore et al. (2004) explicitly define personal identity as those features of the self that underscore individuality precisely because they are not shared with other people; such personal identity is associated with a sense of individual agency, uniqueness and independence, yet it still has a social dimension because its boundaries are actually delineated in contradistinction to the group, social context.

Relational identity refers to the interpersonal social level and focuses on role-related relationships (Sluss \& Ashforth, 2007) with people who the individual personally knows and with whom the individual has regular direct contact (Cheek et al., 2002; Kashima \& Pillai, 2011). Relational identity is defined through interpersonal self-descriptions and characteristics that refer to specific relationships (Brewer \& Chen, 2007) and also by the quality of relatedness, intimacy and interdependence within the relationship (Kashima and Hardie, 2000). In contrast, collective identity is defined by individual's identification with a larger group composed of other people who are in most cases not personally known to the individual but who share what are perceived to be some common characteristics or attributes (Monterde et al., 2015), so again this form of identity is fundamentally social in nature. 
At its heart, the concept of identity implies that the self is reflexive and able to categorise and classify itself in relation to other social categories or classifications (Burke \& Stets, 2009), so social identity is that part of the self-concept resulting from group membership by which individuals define themselves (Tajfel, 2010). Breakwell (2015) suggests that identity structure is determined by two types of process: firstly, absorption of new elements both personal (e.g. values, attitudes) and social (e.g. group membership, interpersonal networks) and the adaptation of these elements to the existing structure of the self. The second process is an evaluation of incorporated elements based mostly on self-interest rather than accuracy. Thus, identity is the result of self-categorisation and allocation of values to parts of the identity (Breakwell, 2015; Burke \& Stets, 2009), and the structure of this identity may both arise from and influence the self-concept and regulate the nature of relationships between the self and others.

Social identity appears to satisfy psychological needs in a global sense (Greenaway et al., 2016) because it helps individuals to find a sense of meaning and belonging leading to a range of positive psychological consequences (e.g. Haslam et al., 2009). A strong social identity has direct individual benefits by engendering a sense of selfesteem (Jetten et al., 2015) which leads to pleasant feelings and enhanced initiative which also fosters the individual belief in agency and the capacity to cope with adverse events better (Khan et al., 2014). Membership in multiple significant social groups boosts personal self-esteem because it leads to more opportunities to be rewarded with praise for socially desirable behaviours (Baumeister et al., 2003), and also because the individual takes pride in, and derives meaning from, influential group memberships (Jetten et al., 2015).

Group membership may also be directly beneficial in its own right because it allows individuals to draw upon social support networks. Indeed, there is increasing evidence that group membership and the strengthening of cognitive social networks may lead to better health and increased well-being (Yamaoka \& Yoshino, 2015) in a range of situations including recovery from depression (Cruwys, Haslam, Dingle, Haslam, et al., 2014; Cruwys, Haslam, Dingle, Jetten, et al., 2014; Cruwys, South, et al., 2015), stroke (Haslam et al., 2008), and cancer (Harwood \& Sparks, 2003). However, these effects may not be uniformly positive or may take time to mature because, as Howell et al. (2014) reported, social ties in an emerging network can be beneficial for psychological well-being by reducing stress and increasing happiness, but can also be harmful for physical health through associated increases in alcohol consumption and minor illness. Nevertheless, once they are formed social identities can protect and enhance mental health because people with stronger social identities are less likely to attribute negative events to internal, fixed or global causes, and instead adopt positive interpretations of stress and failure that reduce depression (Cruwys, South, et al., 2014). Perhaps paradoxically, group membership may also enhance well-being through increasing individuals' sense of personal control, particularly through helping them to develop coping strategies and changing the ways in which they interpret negative life events. Thus, Haslam et al. (2005) found strong positive correlations between social identification, and social support and life satisfaction, as well as a strong negative correlation between social identification and stress. Similarly, Greenaway et al. (2016) reported that identification with political, academic, community and national groups made people feel good, capable and in control of their lives. 
In practical terms the borderline between relational and social identity is not clear, although Lickel et al. (2000) distinguish four types of social groups that can assist in the understanding of different types of identity. Groups established on the basis of intimacy and tasks are characterised by face-to-face interaction among group members and based on personal ties among group members, so this form of social identification is a type of relational identity. In contrast, large identity groups formed on the basis of social categories and loose associations mostly develop through symbolic attachments rather than personal connections between members. Indeed, shared membership can be a function of self-categorisation in terms of the collective identity of a large social group (Lickel et al., 2000). Outten and Schmitt (2015) suggest that adopting a collective identity, such as self-identification with an ethnic group, may also positively impact well-being by reducing stress. At the personal level individuals cope with stress arising from prejudice through proactive avoidance, which is appraising situations to avoid potential instances of unfair discrimination, and also through emotion regulation, that is successfully regulating the negative emotions stemming from perceived unfair discrimination. However, group membership also enables stress coping through collective action, that is appraisals about one's ethnic group working together to better their status, and also social creativity, that is in-group members dealing effectively with negative societal beliefs about their group. When these four coping strategies were studied among Canadians of South Asian heritage it was found that collective action and social creativity were mediators of the relationship between ethnic identification and life satisfaction, showing that group identification promoted well-being for minorities, at least in part, because it encouraged beliefs about one's group responding effectively to unfair discrimination (Outten \& Schmitt, 2015).

Social identity linked to social roles and reputation should be based on public recognition (Cheek et al., 2002), but it also relates to intergroup relations: how people see themselves as members of groups in comparison with other groups (Burke \& Stets, 2009). Most individuals are members of various social groups at the same time, and if the overlap of multiple ingroups is perceived to be high, the social identity structure is simple, whereas, in the situation of low convergence between multiple group memberships, individuals may face identity conflicts when dealing with social identity complexity (Roccas et al., 2008). Various factors can influence the number of identities individuals have and the complexity of their identity hierarchy and structure so, for example, living in a multicultural society may enhance awareness of the gap between ethnic and national identity, as well as increase the salience of social identities related to large social groups (Roccas et al., 2008). If behavioural expectations and resources for different identities are in conflict, then psychological well-being is lowered (Brook et al., 2008) and individuals experience difficulties adapting to the social environment (Phinney, 2011). This may explain why the research evidence linking identification with large social groups to well-being is often contradictory: on one hand, individuals with a stronger collective identity tend to report a higher level of well-being (Dimitrova et al., 2014), and those who highly identify with an ethnic group report higher levels of life satisfaction (Outten \& Schmitt, 2015). There is even a positive relationship between reporting multiple collective group memberships and well-being, but only in those cases where individuals can identify with their multiple groups simultaneously (Yampolsky et al., 2016). Conversely, other 
researchers have found no support for a link between collective group membership based on ethnic or national identity and mental health or life satisfaction (Bratt, 2015).

Alongside ethnic and national identities cultural differences must also be considered because this can also influence life satisfaction (Kreuzbauer et al., 2014). Eastern and Western cultures have different perceptions of the psychological meaning of positive and negative affect and its role in the evaluation of life events. Westerners recall more positive aspects of past experience and link life satisfaction with positive events caused by themselves, whereas Easterners tend to recall both positive and negative affect and correlate life satisfaction with negative events caused by others (Wirtz et al., 2009). Similar comparative research has also shown that the strength of an individual's social network or relational identity, and the associated sense of social support were more closely related to health and well-being outcomes in Asian than Western countries (Yamaoka \& Yoshino, 2015).

The present study was conducted in Singapore, a multicultural and multilingual South East Asian country with a diverse population. The majority of the population in Singapore consists of Chinese, followed by Malays, Indians and a small percentage of 'others'. Given the cultural, religious and linguistic differences between the ethnic groups, the government of Singapore consciously set out to create a 'Singaporean' identity (Tan, 2003) and to promote the idea of a national identity instead of racial or religious one (Kong \& Yeoh, 1997), especially for newly arrived immigrants (Liu, 2014). One of the major parts of this programme was the use of the English language as the primary medium for education, government communication and administration (Wee, 2003). Although it is compulsory for children to study their native language at school and learn about their traditional culture, many families now use English in everyday communication. This creates the interesting phenomenon of grandparents mainly communicating in Chinese, Malay or Tamil, grandchildren speaking mostly English and parents in the middle of this bilingual environment. Alsagoff (2010) posits that 'enforcement' of English as the main language may lead to the development of two aspects of Singaporean identity, global and local, where the former represents Singapore and its citizens as a part of the worldwide community and the economic hub of South East Asia, whereas the latter emphasises links with traditional culture. So-called 'Singlish', a fusion of English and traditional languages, is an example of localising or 'cultural grounding' of language that helps to fulfil a social function and to link various cultural backgrounds with the main medium of communication.

Despite all these efforts, there are still some issues with developing strong sense of identity among Singaporeans. The basis chosen for national identity relates to pragmatism, fluidity and economic realism which may not be sufficient to satisfy needs for relatedness and belonginess because it lacks the deep roots of older cultural traditions (Yang, 2014). Nevertheless, this cross-cultural combination provides a valuable opportunity to explore the different aspects of identity and how they may impact life engagement and well-being in an Asian context.

Despite the abundant evidence that social identity and group membership confers a range of benefits that can mitigate the impact of negative events and positively influence well-being and life satisfaction (Greenaway et al., 2016; Haslam et al., 2005; Kiang et al., 2006; Yamaoka \& Yoshino, 2015), there is a relative paucity of research on how different parts of identity may affect well-being, particularly in an Asian setting. 
Therefore, the present research sets out to address this deficit by investigating how the four areas of identity may contribute to well-being in the Asian context. Based upon previous research it was hypothesised that the identity variables would be predictors of life engagement, and thus also of well-being. It was further hypothesised that life engagement would be a better predictor of well-being than any individual element or combination of social identity variables because, it has been shown that social engagement has significant associations with happiness and well-being (Ford et al., 2015).

\section{Materials and methods}

\section{Variables and measures}

Well-being was measured using the 14 item Warwick-Edinburgh Mental Well-Being Scale (Stewart-Brown \& Janmohamed, 2008). All items are positively stated and evaluate participants experience during the previous two weeks of both affective (e.g. 'I have been feeling cheerful') and cognitive (e.g. 'I have been thinking clearly') components of well-being using a Likert scale from 1 ('none of the time') to 5 ('all of the time'). The overall score is a sum of all items, with a score range 14-70.

Life engagement was measured with the six item Life Engagement Test (Scheier et al., 2006) which assesses life purpose in terms of the extent to which a person engages in activities that are personally valued. It consists of three positive statements (e.g. 'To me, the things I do are all worthwhile'), and three negatively phrased statements (e.g. 'There is not enough purpose in my life') rated on a Likert Scale from 1 (strongly disagree) to 5 (strongly agree). The overall score is a sum of all items, with a score range of 6-30.

Identity was measured by the Aspects of Identity Questionnaire (IV) (Cheek \& Briggs, 2013) which uses statement based items to assess four aspects of identity: personal (e.g. 'My personal goals and hopes for the future'), relational (e.g. 'Being a good friend to those I really care about'), social (e.g. 'My reputation, what others think of me') and collective ('My race or ethnic background') on Likert Scales from 1 ('not important to my sense of who I $\mathrm{am}^{\prime}$ ) to 5 ('Extremely important to my sense of who I am'). Each subscale consists of 7-10 items, so total subscale scores range from 7 to 35 or 10-50. The questionnaire contains a further 10 items that are designed to assess the subjective importance of other dimensions related to the self, but that were not relevant to the present study (Cheek \& Briggs, 2013).

Demographic variables captured were age, gender, ethnicity, educational level and marital status. The last two variables were added to control potential confounds as it has been shown that educational level and relationship status can influence well-being (Kahneman \& Deaton, 2010).

\section{Participants and procedure}

Snowball and opportunity sampling were used to recruit 135 females and 134 males aged from 18 to 35 years old ( $n=269, M=23.88, S D=4.52$ ) who were Singaporean citizens or permanent residents of Singapore. Recruitment took place via the social network of the research team in Singapore. The inclusion criteria for participation included proficiency in English and permanent residential status in Singapore without staying abroad for 
work or study in the preceding year. These criteria helped to exclude participants whose well-being might be affected by stress related to relocation and whose identity could have been impacted by recent experience of staying in another culture. The ethnic heritage of the participants was Chinese (44.2\%), Malay (32.3\%), Indian (16.7\%) and others (6.7\%) thus representing all the major ethnic groups in Singapore. $80 \%$ of respondents were educated to Diploma or Advanced level (18+), 18\% Bachelor's Degree and 1.5\% to postgraduate level. $17.8 \%$ of participants were married, $25.7 \%$ indicated they were in relationships, $2.2 \%$ were divorced and $54.3 \%$ were single. Prior to participation, all respondents were given an information sheet explaining the study and all signed an informed consent form before proceeding to complete the questionnaires. This study was approved by the University Research Ethics Committee.

\section{Results}

In order to test the assumption that there would be moderately strong relationships between all four identity type variables, life engagement and well-being the correlations between the variables were calculated (Table 1).

The correlation coefficients showed that all four types of identity positively correlated with the life engagement scores: personal, $r=.28, p<.01$, relational $r=.26, p<.01$, social $r$ $=.19, p<.01$, collective $r=.21, p<.01$. There were also moderate positive correlations between all four identity orientations and the mental well-being scores: personal, $r$ $=.37, p<.01$, relational $r=.30, p<.01$, social $r=.33, p<.01$, collective $r=.30, p<.01$. Lastly, there was also a positive correlation between life engagement and well-being $r$ $=.47, p<.01$. Thus, four identity orientations as well as life engagement were positively associated with well-being as predicted, lending some support to the first hypothesis.

To test the hypothesis that life-engagement would be a more effective predictor of well-being than the four aspects of social identity because life-engagement subsumes more than identity, multiple regression analyses were conducted. The results showed that life engagement and the four identity variables significantly predicted well-being, $F$ $(5,263)=22.86, p<.001$.

As hypothesised, life engagement was shown to be the strongest predictor of wellbeing, $\beta=.39, p<.001,95 \% \mathrm{Cl}[0.76,1.32]$, whereas the four types of identity were not significant predictors (Table 2). The overall model fit was moderate $R^{2}=.30$ suggesting that life engagement and the identity variables accounted for $30 \%$ of well-being variance.

The fact that all the beta-weights for the identity variables were well below their individual correlation coefficients with well-being, particularly in the cases of the social and

Table 1. Correlations between study variables.

\begin{tabular}{|c|c|c|c|c|c|c|}
\hline Variables & 1 & 2 & 3 & 4 & 5 & 6 \\
\hline 1. Well-being & .91 & & & & & \\
\hline 2. Life engagement & $.47^{* *}$ & .69 & & & & \\
\hline 3. Personal Identity & $.37^{* *}$ & $.28^{* *}$ & .85 & & & \\
\hline 4. Relational Identity & $.30^{* *}$ & $.26^{* *}$ & $.65^{* *}$ & .89 & & \\
\hline 5. Social Identity & $.33^{* *}$ & $.19^{* *}$ & $.65^{* *}$ & $.46^{* *}$ & .83 & \\
\hline 6. Collective Identity & $.30^{* *}$ & $.21^{* *}$ & $.52^{* *}$ & $.41^{* *}$ & $.55^{* *}$ & .79 \\
\hline
\end{tabular}

Note: $n=269$. Scale reliabilities are shown on the diagonal in bold. ${ }^{* *} p<0.01$. 
Table 2. Multiple regression analysis with life engagement and four types of identity as predictors of well-being.

\begin{tabular}{lccc}
\hline & \multicolumn{3}{c}{ Well-being } \\
\cline { 2 - 4 } & $\mathrm{B}$ & $S E(\mathrm{~B})$ & $\beta$ \\
\hline Life Engagement & 1.04 & .14 & $.39^{* *}$ \\
Personal Identity & .17 & .12 & .11 \\
Relational Identity & .05 & .09 & .04 \\
Social Identity & .25 & .13 & .13 \\
Collective Identity & .10 & .10 & .07 \\
\hline
\end{tabular}

${ }^{* *} p<0.01$.

collective identity scales, suggested that life-engagement had subsumed the identity variance in line with the second hypothesis. However, the high correlations between the individual identity variables shown in Table 1 could also have indicated that each of the four identity scales were tapping a more fundamental identity construct that is common across each of the orientations and that was parcelled out by the regression. If so, then the apparent predictive power of each identity scale when correlated with life-engagement could actually be a function of this fundamental core identity variance. In order to test this proposition, the identity variables were regressed directly on the well-being scale.

The results show that well-being was significantly predicted by all the identity variables combined, $F(4,264)=12.78, p<.001$, with the only one significant predictor being personal identity $\beta=.18, p=.04,95 \% \mathrm{Cl}[0.01,0.52]$, but none of the other identity orientations was a significant predictor of well-being on its own (Table 3 ). Social identity was the second contributor to well-being $\beta=.12, p=.13,95 \% \mathrm{Cl}[-0.06,0.53]$, following by collective $\beta=.10, p=.15,95 \% \mathrm{Cl}[-0.06,0.38]$ and relational $\beta=.09, p=.25,95 \% \mathrm{Cl}[-0.09,0.33]$ identities. The overall model fit was $R^{2}=0.16$, so all four identity orientations combined accounted for a reasonable proportion of the well-being variance, but only approximately half the proportion of variance accounted for when life engagement was included in the model. This again lent strong support to the second hypothesis that life engagement subsumed some identity-related variance and also accounted for other factors predictive of well-being.

As the beta weights for the identity variables were lower than the corresponding bivariate correlation coefficients with well-being, it indeed appeared that there was some common variance shared across the identity variables, but the fact that the beta weights were in most cases still moderately large also suggested that each identity scale tapped a core of unique variance. In order to explore the extent to which life-engagement subsumed at least some of the variance unique to each identity variable and to assess the extent to which the identity variables were independent and direct predictors

Table 3. Multiple regression analysis with four types of identity as predictors of well-being.

\begin{tabular}{lccc}
\hline & \multicolumn{3}{c}{ Well-being } \\
\cline { 2 - 4 } & $\mathrm{B}$ & SE(B) & $\beta$ \\
\hline Personal Identity & .26 & .13 & $.18^{*}$ \\
Relational Identity & .12 & .11 & .09 \\
Social Identity & .23 & .15 & .12 \\
Collective Identity & .16 & .11 & .10 \\
\hline${ }^{*} p<0.05$. & & &
\end{tabular}


of well-being without the intervening life-engagement construct, a stepwise regression analysis was conducted.

As expected, the regression model demonstrated that life engagement was a significant predictor of well-being $\beta=.40, p<.001,95 \% \mathrm{Cl}[0.78,1.33]$, but that social identity $\beta=.16, p=.02,95 \% \mathrm{Cl}[0.05,0.56]$ and personal identity $\beta=.15, p=.03,95 \% \mathrm{Cl}[0.02$, $0.42]$, were also significant and independent predictors, whereas the relational and collective identity orientations were excluded from the model (Table 4). This suggested that the variance associated with the relational and collective identity scales was subsumed within life-engagement, but also that there was some unique variance associated with the social and personal identity scales which was independently predictive of well-being such that the second hypothesis was only partially supported because life engagement did not subsume all of the identity variance that was predictive of well-being.

Overall, these results showed that personal, relational, social and collective identity contribute to life-engagement and well-being, that relational and collective identity may be subsumed within life-engagement, but that personal and social identity are independent predictors of well-being beyond life-engagement. This provides some support for the eudaemonic theory that identity is associated with life engagement and that life engagement with some aspects of identity are in turn associated with well-being.

\section{Discussion}

As was hypothesised the identity variables were moderate predictors of life engagement and well-being, and life engagement subsumed some identity variance to be a much stronger overall predictor of well-being. This lent clear support to the eudaemonic model that individuals achieve well-being through actively engaging in activities which develop a life that is both satisfying and meaningful (Deci \& Ryan, 2008; Schueller \& Seligman, 2010).

However, contrary to our predictions, life engagement did not subsume all the identity variables such that social identity and personal identity were shown to be independent predictors of well-being alongside life engagement. Social identity is associated with intergroup relationships and is linked to social roles and social norms, so it is influenced by how strongly an individual identifies with a particular social group. Tajfel (2010) posits that individuals experience a cognitive change in self-representation at the categorisation stage when they identify with the group, and that this is then followed by an affective component arising from identification with group members. So, just being a part of a social group is not sufficient to develop a strong sense of social identity and a true sense of

Table 4. Stepwise regression analysis with life engagement and four types of identity as predictors of well-being.

\begin{tabular}{llccccc}
\hline & \multicolumn{1}{c}{ Predictor } & $\mathrm{B}$ & $S E(\mathrm{~B})$ & $\beta$ & $R^{2}$ & $F$ \\
\hline Step 1 & Life Engagement & 1.25 & .14 & $.47^{* *}$ & .22 & $77.18^{* *}$ \\
Step 2 & Life Engagement & 1.12 & .14 & $.43^{* *}$ & .29 & $53.36^{* *}$ \\
& Social Identity & .48 & .10 & $.25^{* *}$ & & $37.70^{* *}$ \\
Step 3 & Life Engagement & 1.06 & .14 & $.40^{* *}$ & .30 & $.16^{*}$ \\
& Social Identity & .30 & .13 & & $.15^{*}$ \\
& Personal Identity & .22 & .10 & & \\
\hline
\end{tabular}

${ }^{* *} p<.01 ;{ }^{*} p<0.05$. 
social identity must be supported by positive emotions related to inclusion in the group. Once the sense of belonging to the group is based not only on cognitive categorisation but also an emotional attachment to the group, then social identity becomes salient across many aspects of life and promotes well-being. Thus, social identity satisfies psychological needs in a global sense, most obviously, the need to belong which leads to a sense of a meaningful existence with respect to others (Greenaway et al., 2015) and this may be one reason why it significantly predicts well-being therefore extends beyond life engagement. Social identity has also been shown to be associated with a range of health benefits, and individuals with extensive social networks have a higher probability of living longer with lessened cognitive decline, display greater resistance to infectious illness, and they also deploy better coping strategies when dealing with chronic or life-threatening diseases (Cohen \& Janicki-Deverts, 2009). Social identity can also alter attribution styles when assessing life events so that individuals are able to face stress or failure more positively (Cruwys et al., 2015), and feeling connected with and participating in group activities can boost positive emotions, alleviate depression leading to better health (Friedman \& Kern, 2014; Santos et al., 2013) and increases in life span (Xu \& Roberts, 2010). Thus, it would appear that social identity may have a range of positive effects beyond life engagement and this may explain why some social identity variance is directly predictive of well-being.

Personal identity, on the other hand, is that part of the individual self that distinguishes a person from others, that provides a sense of autonomy and that establishes personal values. This type of identity creates a sense of self-control and the capacity to exercise choice and to determine the outcomes individuals will obtain as a result of different behavioural strategies. The perception of control is essential for psychological functioning and is an adaptive strategy to an ever-changing environment because the ability to produce the desired results positively contributes to a sense of competence and autonomy that influences cognition and behaviour via motivational processing and emotional regulation (Leotti et al., 2010). It is this sense of individual autonomy that may explain why personal identity was an independent predictor of well-being and because the effects of perceived autonomy are independent from the social aspects of life engagement and also from social identity in their association with, for example, health-related attitudes and behaviour (Chatzisarantis et al., 2009). Thus, some aspects of personal and social identities may both positively predict health and well-being directly but may do so through related but clearly distinct mechanisms.

Relational identity deals with an individual's perception of roles in interpersonal relationships and the quality of those relationships with significant others on an everyday basis (Brewer \& Chen, 2007; Kashima \& Pillai, 2011; Sluss \& Ashforth, 2007). Kreuzbauer et al. (2014) found that relational identity amongst Asians was associated with higher life engagement, but in the present research relational identity was not significantly predictive of well-being directly and was subsumed in general life engagement. This may have been because the participants in the present study were relatively youthful so had limited experience of relationships and had not yet established the strong personal meta-narratives that are essential to establishing relational identity (Bauer et al., 2008). Alternatively, as millennials express their relational identity much more online (Valkenburg et al., 2006), it is possible that the Aspects of Identity Questionnaire (IV) (Cheek \& Briggs, 2013) did not tap the relational domain sufficiently or that participants had relatively weak 
relational identities because higher social media use is associated with lower bonding and increased loneliness (Burke et al., 2010).

Given that the present research was conducted in a supposedly collectivist Asian society, it was interesting, that the collective identity orientation had a comparatively low contribution to well-being and was virtually completely subsumed in life engagement. However, even if individuals have a sense of collective identity the evidence about the importance of collective identity to well-being is mixed, primarily because there are competing definitions of the collective, with some suggesting that collective identity is broadly symbolic (Roccas et al., 2008), whereas other researchers emphasise multiple and even conflicting collective identities along ethnic, religious, familial, etc. lines (Dimitrova et al., 2014). Moreover, multiple identities only benefit subjective well-being when all of them are in harmony with each other or when there is a clear hierarchy of identities based on importance and social context (Brook et al., 2008; Jetten et al., 2015). Thus, the multifaceted nature of collective identity in an ethnically heterogeneous, mixed linguistic, multireligious society such as Singapore may simply be too complex for a consistent collective identity to emerge for many individuals, and this may be why collective identity was not significant predictor of well-being within the present research.

This latter point may also help to explain why personal and social identity proved to be more significant predictors that those identity orientations based, in simple terms, on family and ethnicity despite the fact that these latter aspects of identity have been found to be significant predictors of well-being in other Asian samples. The Singaporean government actively encourages the formation of social groups through its citizenship education and community development policies, and through national service for all young men (Sim \& Print, 2005). Once such groups are established at school, in government sponsored activities, the workplace, etc. it is very easy to maintain them because Singapore is so geographically compact and every location is within easy travelling distance of every other location. Furthermore, given the multi-ethnic nature of the city state and a bloody history of inter-communal violence in the years immediately after independence from Britain and during the intervening period that resulted in secession from Malaysia, the Singaporean government has deliberately fostered the sense of a single national as opposed to multiple racial or religious identities (Kong \& Yeoh, 1997). This may, therefore, have led Singaporeans to emphasise their social identity at the expense of any collective identity established along racial or religious lines, which would explain why collective identity was subsumed in life engagement yet social identity made a unique contribution to well-being. This could mean that collective identity along racial and religious lines has been effectively replaced by other forms of identity, but it could also indicate that the homogenous Singaporean identity has yet to establish itself powerfully enough to become an essential part of identity (Ortmann, 2009), though only further research could resolve this point definitively.

Singapore also adopted a range of social and educational policies to promote the use of English and western modes of education (Rubdy, 2001). On one level this may have introduced attitudes and expectations that are more aligned with Western rather than Asian relational identity norms, as may be evidenced, for example, by the controversial growth of Western-style care homes for the elderly replacing traditional family-based care (Torrendo, 2018). On another level, the widespread adoption of English in family communication has led to clear distinctions developing between the generations, with 
youngsters much more likely to use English in everyday communication than their parents and grandparents. Even though every Singaporean child receives instruction in their socalled mother tongue, the non-English languages taught are invariably the standardised versions of the language rather than the demotic dialects spoken by elders so even youngsters speaking fluent Mandarin or Malay struggle to comprehend Hakka or Johorean (Hansen Edwards, 2017). This, coupled with the fast growth of new religious and cultural affiliations may mean that relational identities have receded to be replaced much more with social and personal identities that chime more with Western norms, though this must of course be explored through further research.

Indeed, the simple quantitative approach to understanding the links between identity and well-being may not be sufficient to explore the ways in which identities evolve and interact through time, so future researchers may wish to consider conducting qualitative explorations to establish the elements that contribute to each type of identity and their relative importance in well-being. As already discussed, millennials also express their identity in different ways, most notably online (Valkenburg et al., 2006) and this is clearly an area that warrants further research to mark out the social media domains of identity. However, it is also possible that the link between identity and well-being actually functions at higher levels of psychosocial integration (Bauer et al., 2008) which would imply that traditional models of identity may need to be rethought and may even be replaced by a greater emphasis on ego development as a driver of well-being. The data presented in this study suggest that an important transition may be underway as collective and relational identities become less relevant than personal and social identities to life engagement and well-being, at least among young Singaporeans (Tan \& Tambyah, 2016). Now it remains to discover if these changes are a function of youth, of fundamental changes in Asian societies, of both or of neither.

\section{Conclusion}

The eudaemonic tradition posits that a key element of well-being is life engagement which is achieved by actively pursuing a meaningful and deeply satisfying way of living. The present research suggests that the ways in which young Singaporeans conceive of their identity makes a significant contribution to their life engagement and well-being, but that there appear to be differences in the size and nature of the relationships between the various forms of identity, life engagement and well-being. Collective and relational identities appear to be almost wholly subsumed within life engagement, whereas personal and social identities appear to be important components of life engagement, as well as being independently predictive of well-being. It is proposed that these differences reflect changes in perceptions among young Singaporeans resulting in collective and relational identities that are perhaps weaker and no longer conform to traditional Asian patterns, whereas their sense of personal and social identities are indicative of more Western approaches to both life engagement and well-being.

\section{Disclosure statement}

No potential conflict of interest was reported by the author(s). 


\section{ORCID}

Elizaveta Berezina (1) http://orcid.org/0000-0003-1972-8133

Colin Mathew Hugues Desaguliers Gill (1D) http://orcid.org/0000-0002-3225-246X

Inna Bovina (D) http://orcid.org/0000-0002-9497-6199

\section{References}

Alsagoff, L. (2010). English in Singapore: Culture, capital and identity in linguistic variation. World Englishes, 29(3), 336-348. https://doi.org/10.1111/j.1467-971X.2010.01658.x

Ashmore, R. D., Deaux, K., \& McLaughlin-Volpe, T. (2004). An organizing framework for collective identity: Articulation and significance of multidimensionality. Psychological Bulletin, 130(1), 80-114. https://doi.org/10.1037/0033-2909.130.1.80

Bauer, J. J., McAdams, D. P., \& Pals, J. L. (2008). Narrative identity and eudaimonic well-being. Journal of Happiness Studies, 9(1), 81-104. https://doi.org/10.1007/s10902-006-9021-6

Baumeister, R. F., Campbell, J. D., Krueger, J. I., \& Vohs, K. D. (2003). Does high self-esteem cause better performance, interpersonal success, happiness, or healthier lifestyles? Psychological Science in the Public Interest, 4(1), 1-44. https://doi.org/10.1111/1529-1006.01431

Bratt, C. (2015). One of few or one of many: Social identification and psychological well-being among minority youth. British Journal of Social Psychology, 54(4), 671-694. https://doi.org/10.1111/bjso. 12105

Breakwell, G. M. (2015). Coping with threatened identities (Vol. 5). Psychology Press.

Brewer, M. B., \& Chen, Y. R. (2007). Where (who) are collectives in collectivism? Toward conceptual clarification of individualism and collectivism. Psychological Review, 114(1), 133-151. https://doi. org/10.1037/0033-295X.114.1.133

Brook, A. T., Garcia, J., \& Fleming, M. A. (2008). The effects of multiple identities on psychological wellbeing. Personality and Social Psychology Bulletin, 34(12), 1588-1600. https://doi.org/10.1177/ 0146167208324629

Burke, M., Marlow, C., \& Lento, T. (2010). Social network activity and social well-being. In Scott Hudson \& Geraldine Fitzpatrick (Eds.), Proceedings of the SIGCHI conference on human factors in computing systems (pp. 1909-1912). ACM.

Burke, P. J., \& Stets, J. E. (2009). Identity theory. Oxford University Press.

Chatzisarantis, N. L., Hagger, M. S., Wang, C. J., \& Thøgersen-Ntoumani, C. (2009). The effects of social identity and perceived autonomy support on health behaviour within the theory of planned behaviour. Current Psychology, 28(1), 55-68. https://doi.org/10.1007/s12144-009-9043-4

Cheek, J. M., \& Briggs, S. R. (2013). Aspects of Identity Questionnaire (AIQ-IV). Measurement Instrument Database for the Social Science. www.midss.ie

Cheek, J. M., Smith, S. M., \& Tropp, L. R. (2002). Relational identity orientation: A fourth scale for the AIQ. In Meeting of the Society for Personality and Social Psychology, Savannah, GA.

Cohen, S., \& Janicki-Deverts, D. (2009). Can we improve our physical health by altering our social networks? Perspectives on Psychological Science, 4(4), 375-378. https://doi.org/10.1111/j.1745-6924. 2009.01141.x

Cruwys, T., Haslam, S. A., Dingle, G. A., Haslam, C., \& Jetten, J. (2014). Depression and social identity: An integrative review. Personality and Social Psychology Review, 18(3), 215-238. https://doi.org/10. $1177 / 1088868314523839$

Cruwys, T., Haslam, S. A., Dingle, G. A., Jetten, J., Hornsey, M. J., Chong, E. D., \& Oei, T. P. (2014). Feeling connected again: Interventions that increase social identification reduce depression symptoms in community and clinical settings. Journal of Affective Disorders, 159, 139-146. https://doi.org/10. 1016/j.jad.2014.02.019

Cruwys, T., South, E. I., Greenaway, K. H., \& Haslam, S. A. (2015). Social identity reduces depression by fostering positive attributions. Social Psychological and Personality Science, 6(1), 65-74. https://doi. org/10.1177/1948550614543309 
Deci, E. L., \& Ryan, R. M. (2008). Hedonia, eudaimonia, and well-being: An introduction. Journal of Happiness Studies, 9(1), 1-11. https://doi.org/10.1007/s10902-006-9018-1

Diener, E., \& Biswas-Diener, R. (2008). Measuring psychological wealth: Your well-being balance sheet. In Ed Diener (Ed.), Happiness: Unlocking the mysteries of psychological wealth (pp. 234243). Wiley-Blackwell.

Diener, E., Lucas, R. E., \& Oishi, S. (2018). Advances and open questions in the science of subjective well-being. Collabra: Psychology, 4(1), 15. https://doi.org/10.1525/collabra.115

Diener, E., Ng, W., Harter, J., \& Arora, R. (2010). Wealth and happiness across the world: Material prosperity predicts life evaluation, whereas psychosocial prosperity predicts positive feeling. Journal of Personality and Social Psychology, 99(1), 52-61. https://doi.org/10.1037/a0018066

Dimitrova, R., Chasiotis, A., Bender, M., \& van de Vijver, F. J. (2014). From a collection of identities to collective identity: Evidence from mainstream and minority adolescents in Bulgaria. Cross-Cultural Research, 48(4), 339-367. https://doi.org/10.1177/1069397114523922

Ford, B. Q., Dmitrieva, J. O., Heller, D., Chentsova-Dutton, Y., Grossmann, I., Tamir, M., Uchida, Y., Koopmann-Holm, B., Floerke, V. A., Uhrig, M., \& Bokhan, T. (2015). Culture shapes whether the pursuit of happiness predicts higher or lower well-being. Journal of Experimental Psychology: General, 144(6), 1053-1062. https://doi.org/10.1037/xge0000108

Friedman, H. S., \& Kern, M. L. (2014). Personality, well-being, and health. Annual Review of Psychology, 65(2014), 719-742. https://doi.org/10.1146/annurev-psych-010213-115123

Greenaway, K. H., Cruwys, T., Haslam, S. A., \& Jetten, J. (2016). Social identities promote well-being because they satisfy global psychological needs. European Journal of Social Psychology, 46(3), 294-307. https://doi.org/10.1002/ejsp.2169

Greenaway, K. H., Haslam, S. A., Cruwys, T., Branscombe, N. R., Ysseldyk, R., \& Heldreth, C. (2015). From "we" to "me": Group identification enhances perceived personal control with consequences for health and well-being.. Journal of Personality and Social Psychology, 109(1), 53-74. https://doi. org/10.1037/pspi0000019

Hansen Edwards, J. G. (2017). Defining 'native speaker'in multilingual settings: English as a native language in Asia. Journal of Multilingual and Multicultural Development, 38(9), 757-771. https:// doi.org/10.1080/01434632.2016.1257627

Harwood, J., \& Sparks, L. (2003). Social identity and health: An intergroup communication approach to cancer. Health Communication, 15(2), 145-159. https://doi.org/10.1207/S15327027HC1502_3

Haslam, C., Holme, A., Haslam, S. A., Iyer, A., Jetten, J., \& Williams, W. H. (2008). Maintaining group memberships: Social identity continuity predicts well-being after stroke. Neuropsychological Rehabilitation, 18(5-6), 671-691. https://doi.org/10.1080/09602010701643449

Haslam, S. A., Jetten, J., Postmes, T., \& Haslam, C. (2009). Social identity, health and well-being: An emerging agenda for applied psychology. Applied Psychology, 58(1), 1-23. https://doi.org/10. 1111/j.1464-0597.2008.00379.x

Haslam, S. A., O'Brien, A., Jetten, J., Vormedal, K., \& Penna, S. (2005). Taking the strain: Social identity, social support, and the experience of stress. British Journal of Social Psychology, 44(3), 355-370. https://doi.org/10.1348/014466605X37468

Howell, J. L., Koudenburg, N., Loschelder, D. D., Weston, D., Fransen, K., De Dominicis, S., Gallagher, S., \& Haslam, S. A. (2014). Happy but unhealthy: The relationship between social ties and health in an emerging network. European Journal of Social Psychology, 44(6), 612-621. https://doi.org/10.1002/ ejsp.2030

Jetten, J., Branscombe, N. R., Haslam, S. A., Haslam, C., Cruwys, T., Jones, J. M., Cui, L., Dingle, G., Liu, J., Murphy, S., \& Thai, A. (2015). Having a lot of a good thing: Multiple important group memberships as a source of self-esteem. PLOS ONE, 10(5), e0124609. https://doi.org/10.1371/journal.pone. 0124609

Kahneman, D., \& Deaton, A. (2010). High income improves evaluation of life but not emotional wellbeing. Proceedings of the National Academy of Sciences, 107(38), 16489-16493. https://doi.org/10. 1073/pnas.1011492107

Kashima, Emiko S., \& Hardie, Elizabeth A. (2000). The development and validation of the Relational, Individual, and Collective self-aspects (RIC) Scale. Asian Journal of Social Psychology, 3(1), 19-48. https://doi.org/10.1111/ajsp.2000.3.issue-1 
Kashima, E. S., \& Pillai, D. (2011). Identity development in cultural transition: The role of need for closure. Journal of Cross-Cultural Psychology, 42(5), 725-739. https://doi.org/10.1177/ 0022022110362749

Khan, S. S., Hopkins, N., Tewari, S., Srinivasan, N., Reicher, S. D., \& Ozakinci, G. (2014). Efficacy and wellbeing in rural north India: The role of social identification with a large-scale community identity. European Journal of Social Psychology, 44(7), 787-798. https://doi.org/10.1002/ejsp.2060

Kiang, L., Yip, T., Gonzales-Backen, M., Witkow, M., \& Fuligni, A. J. (2006). Ethnic identity and the daily psychological well-being of adolescents from Mexican and Chinese backgrounds. Child Development, 77(5), 1338-1350. https://doi.org/10.1111/j.1467-8624.2006.00938.x

Knowles, M. L., \& Gardner, W. L. (2008). Benefits of membership: The activation and amplification of group identities in response to social rejection. Personality and Social Psychology Bulletin, 34(9), 1200-1213. https://doi.org/10.1177/0146167208320062

Kong, L., \& Yeoh, B. S. (1997). The construction of national identity through the production of ritual and spectacle: An analysis of National Day parades in Singapore. Political Geography, 16(3), 213239. https://doi.org/10.1016/0962-6298(95)00135-2

Kreuzbauer, R., Chiu, C. Y., Lin, S., \& Bae, S. H. (2014). When does life satisfaction accompany relational identity signaling: A cross-cultural analysis. Journal of Cross-Cultural Psychology. https://doi.org/10. $1177 / 0022022113518369$.

Leotti, L. A., lyengar, S. S., \& Ochsner, K. N. (2010). Born to choose: The origins and value of the need for control. Trends in Cognitive Sciences, 14(10), 457-463. https://doi.org/10.1016/j.tics.2010.08.001

Lickel, B., Hamilton, D. L., Wieczorkowska, G., Lewis, A., Sherman, S. J., \& Uhles, A. N. (2000). Varieties of groups and the perception of group entitativity. Journal of Personality and Social Psychology, 78(2), 223-246. https://doi.org/10.1037/0022-3514.78.2.223

Liu, H. (2014). Beyond co-ethnicity: The politics of differentiating and integrating new immigrants in Singapore. Ethnic and Racial Studies, 37(7), 1225-1238. https://doi.org/10.1080/01419870.2014. 892630

Luhmann, M., Hofmann, W., Eid, M., \& Lucas, R. E. (2012). Subjective well-being and adaptation to life events: A meta-analysis on differences between cognitive and affective well-being. https://doi. org/10.1037/a0025948

Monterde, A., Calleja-López, A., Aguilera, M., Barandiaran, X. E., \& Postill, J. (2015). Multitudinous identities: A qualitative and network analysis of the $15 \mathrm{M}$ collective identity. Information, Communication and Society, 18(8), 930-950. https://doi.org/10.1080/1369118X.2015.1043315

Ortmann, S. (2009). Singapore: The politics of inventing national identity. Journal of Current Southeast Asian Affairs, 28(4), 23-46. https://doi.org/10.1177/186810340902800402

Outten, H. R., \& Schmitt, M. T. (2015). The more "intergroup" the merrier? The relationship between ethnic identification, coping options, and life satisfaction among South Asian Canadians.. Canadian Journal of Behavioural Science/Revue canadienne des sciences du comportement, 47(1), 12-20. https://doi.org/10.1037/a0035907

Phinney, J. S. (2011). Increasing our understanding of the acculturation gap: A way forward. Human Development, 53(6), 350-355. https://doi.org/10.1159/000323301

Roccas, S., Sagiv, L., Schwartz, S., Halevy, N., \& Eidelson, R. (2008). Toward a unifying model of identification with groups: Integrating theoretical perspectives. Personality and Social Psychology Review, 12(3), 280-306. https://doi.org/10.1177/1088868308319225

Rubdy, R. (2001). Creative destruction: Singapore's speak good English movement. World Englishes, 20(3), 341-355. https://doi.org/10.1111/1467-971X.00219

Santos, V., Paes, F., Pereira, V., Arias-Carrión, O., Silva, A. C., Carta, M. G., Nardi, A. E., Machado, S. (2013). The role of positive emotion and contributions of positive psychology in depression treatment: Systematic review. Clinical Practice \& Epidemiology in Mental Health, 9(1), 221-237. https://doi. org/10.2174/1745017901309010221

Scheier, Michael F., Wrosch, Carsten, Baum, Andrew, Cohen, Sheldon, Martire, Lynn M., Matthews, Karen A., Schulz, Richard, \& Zdaniuk, Bozena. (2006). The Life Engagement Test: Assessing Purpose in Life. Journal of Behavioral Medicine, 29(3), 291-298. https://doi.org/10.1007/s10865005-9044-1 
Schueller, S. M., \& Seligman, M. E. (2010). Pursuit of pleasure, engagement, and meaning: Relationships to subjective and objective measures of well-being. The Journal of Positive Psychology, 5(4), 253-263. https://doi.org/10.1080/17439761003794130

Sheldon, K. M., \& Niemiec, C. P. (2006). It's not just the amount that counts: Balanced need satisfaction also affects well-being. Journal of Personality and Social Psychology, 91(2), 331-341. https://doi.org/ 10.1037/0022-3514.91.2.331

Sim, J. B. Y., \& Print, M. (2005). Citizenship education and social studies in Singapore: A national agenda. International Journal of Citizenship and Teacher Education, 1(1), 58-73.

Sluss, D. M., \& Ashforth, B. E. (2007). Relational identity and identification: Defining ourselves through work relationships. Academy of Management Review, 32(1), 9-32. https://doi.org/10.5465/amr. 2007.23463672

Smith, C. V. (2007). In pursuit of 'good' sex: Self-determination and the sexual experience. Journal of Social and Personal Relationships, 24(1), 69-85. https://doi.org/10.1177/0265407507072589

Stewart-Brown, S., \& Janmohamed, K. (2008). Warwick-Edinburgh mental well-being scale. User guide. Version, 1.

Tajfel, H. (2010). 16. Instrumentality, identity and social comparisons. In Henri Tajfel (Ed.), Social identity and intergroup relations (pp. 483). Cambridge University Press.

Tan, E. K. (2003). Re-engaging Chineseness: Political, economic and cultural imperatives of nationbuilding in Singapore. The China Quarterly, 175, 751-774. https://doi.org/10.1017/ S0305741003000432

Tan, S. J., \& Tambyah, S. K. (2016). Shifting values and life satisfaction: A sequential cross-sectional study of the influence of values on subjective wellbeing in Singapore. Social Indicators Research, 127(3), 1391-1416. https://doi.org/10.1007/s11205-015-1015-5

Torrendo, T. (2018, November 18). Old and home alone: the Sensors change in Singapore the life of the pensioner. Daily News. https://www.dailynewsdir.com/old-and-home-alone-the-sensorschange-in-singapore-the-life-of-the-pensioner

Valkenburg, P. M., Peter, J., \& Schouten, A. P. (2006). Friend networking sites and their relationship to adolescents' well-being and social self-esteem. CyberPsychology and Behavior, 9(5), 584-590. https://doi.org/10.1089/cpb.2006.9.584

Wee, L. (2003). Linguistic instrumentalism in Singapore. Journal of Multilingual and Multicultural Development, 24(3), 211-224. https://doi.org/10.1080/01434630308666499

Wirtz, D., Chiu, C. Y., Diener, E., \& Oishi, S. (2009). What constitutes a good life? Cultural differences in the role of positive and negative affect in subjective well-being. Journal of Personality, 77(4), 11671196. https://doi.org/10.1111/j.1467-6494.2009.00578.x

World Health Organization. (2014). Mental health: A state of well-being. http://www.who.int/features/ factfiles/mental_health/en/

$\mathrm{Xu}$, J., \& Roberts, R. E. (2010). The power of positive emotions: It's a matter of life or death-Subjective well-being and longevity over 28 years in a general population. Health Psychology, 29(1), 9-19. https://doi.org/10.1037/a0016767

Yamaoka, K., \& Yoshino, R. (2015). Relation of social capital to health and well-being in the Asia Pacific values survey: A population-based study. Behaviormetrika, 42(2), 209-229. https://doi.org/10.2333/ bhmk.42.209

Yampolsky, M. A., Amiot, C. E., \& de la Sablonnière, R. (2016). The Multicultural Identity Integration Scale (MULTIIS): Developing a comprehensive measure for configuring one's multiple cultural identities within the self. Cultural Diversity and Ethnic Minority Psychology, 22(2), 166-184. https://doi.org/10.1037/cdp0000043

Yang, P. (2014). "Authenticity" and "foreign talent" in Singapore: The relative and negative logic of national identity. Journal of Social Issues in Southeast Asia, 29(2), 408-437. https://doi.org/10. 1355/sj29-2f 